\title{
Alemtuzumab Induction is Associated with a Lower Incidence of BK Virus Nephropathy Compared with IL2R Induction
}

Alexander Gueret-Wardle, Michelle Willicombe, Gaetano Lucisano, Sevda Hassan and David Taube

Imperial College kidney and Transplant Centre, Hammersmith Hospital, London

Introduction: BK polyoma virus associated nephropathy [BKVAN] is a major cause of allograft dysfunction and graft loss occurring in up to $10 \%$ of kidney allograft recipients with a mean time to diagnosis of 120 days.

BK virus nephropathy is manifested by tubulo-interstitial nephritis and ureteric stenosis. BK virus can potentially cause haemorrhagic cystitis although this is rarely seen amongst renal transplant recipients and is more common in allogenic bone marrow transplantation.

Although BKVAN is associated with a higher exposure to immunosuppressive agents, there are few reports describing the incidence and outcomes of BKVAN in patients receiving Alemtuzumab induction.

Methods: 1503 low risk kidney only transplant recipients received a steroid sparing regimen with Alemtuzumab induction and tacrolimus monotherapy or IL2R induction with tacrolimus and MMF. The demographics of this cohort are shown in Table 1.

BKVAN was only diagnosed by allograft biopsy [viral inclusions, tubular injury and interstitial infiltrates in the areas of tubular damage]. BKVAN was treated by MMF cessation and/or tacrolimus dose reduction.

\begin{tabular}{|c|c|c|c|c|}
\hline Variable & & BK $N=68$ & No BK $N=1435$ & P value \\
\hline Gender & $\begin{array}{l}\mathrm{M} \\
\mathrm{F}\end{array}$ & $\begin{array}{l}40 \\
28\end{array}$ & $\begin{array}{l}937 \\
498\end{array}$ & 0.27 \\
\hline Age at tx & Mean (yrs) & $51.83 \pm 12.89$ & $49.86 \pm 13.17$ & 0.23 \\
\hline Ethnicity & $\begin{array}{l}\text { Caucasian } \\
\text { South Asian } \\
\text { Black } \\
\text { Other }\end{array}$ & $\begin{array}{l}25 \\
25 \\
14 \\
4\end{array}$ & $\begin{array}{l}620 \\
466 \\
222 \\
127\end{array}$ & 0.59 \\
\hline $\begin{array}{l}\text { Type of } \\
\text { graft }\end{array}$ & $\begin{array}{l}\text { LD } \\
\text { DD }\end{array}$ & $\begin{array}{l}31 \\
37\end{array}$ & $\begin{array}{l}605 \\
830\end{array}$ & 0.58 \\
\hline Graft no. & $\begin{array}{l}1^{\text {st }} \\
>2\end{array}$ & $\begin{array}{l}61 \\
7\end{array}$ & $\begin{array}{l}1259 \\
176\end{array}$ & 0.63 \\
\hline Induction & $\begin{array}{l}\text { Alemtuzumab } \\
\text { IL2RA }\end{array}$ & $\begin{array}{l}50 \\
18\end{array}$ & $\begin{array}{l}1261 \\
174\end{array}$ & 0.0005 \\
\hline $\begin{array}{l}\text { Pre- } \\
\text { emptive }\end{array}$ & $\begin{array}{l}\mathrm{Y} \\
\mathrm{N}\end{array}$ & $\begin{array}{l}10 \\
58\end{array}$ & $\begin{array}{l}298 \\
1137\end{array}$ & 0.23 \\
\hline Diabetes & $\begin{array}{l}\mathrm{Y} \\
\mathrm{N}\end{array}$ & $\begin{array}{l}17 \\
51\end{array}$ & $\begin{array}{l}335 \\
1099\end{array}$ & 0.76 \\
\hline Sensitised & $\begin{array}{l}\text { Preformed } \\
\text { Non-sensitised } \\
\text { Sensitised }\end{array}$ & $\begin{array}{l}8 \\
44 \\
16\end{array}$ & $\begin{array}{l}94 \\
940 \\
400\end{array}$ & 0.22 \\
\hline $\begin{array}{l}\text { HLA } \\
\text { mismatch }\end{array}$ & Median (IQR) & $4(3-4)$ & $3(2-4)$ & 0.055 \\
\hline $\begin{array}{l}\text { Wt at } \\
\text { transplant }\end{array}$ & Mean $(\mathrm{kg})$ & $71.08 \pm 14.53$ & $75.58 \pm 17.65$ & 0.039 \\
\hline
\end{tabular}

Results: 68/1503 [4.5\%] patients developed BKVAN. Patients receiving Alemtuzumab induction had a significantly lower incidence of BKVAN 50/1503 [3.81\%] compared with patients receiving IL2R induction 18/192 [9.4\%, p=0.0019] Graph 1. Mean time to development of BKVAN was 370 days. Mean death censored allograft survival was $7.47 \pm 0.55$ years for both groups. However censored allograft survival was superior in those patients on MMF at the time of BKVAN diagnosis compared to CNIs alone [p=0.023] Graph 2.

\section{BK Free Allograft Survival With Az vs IL2RA}

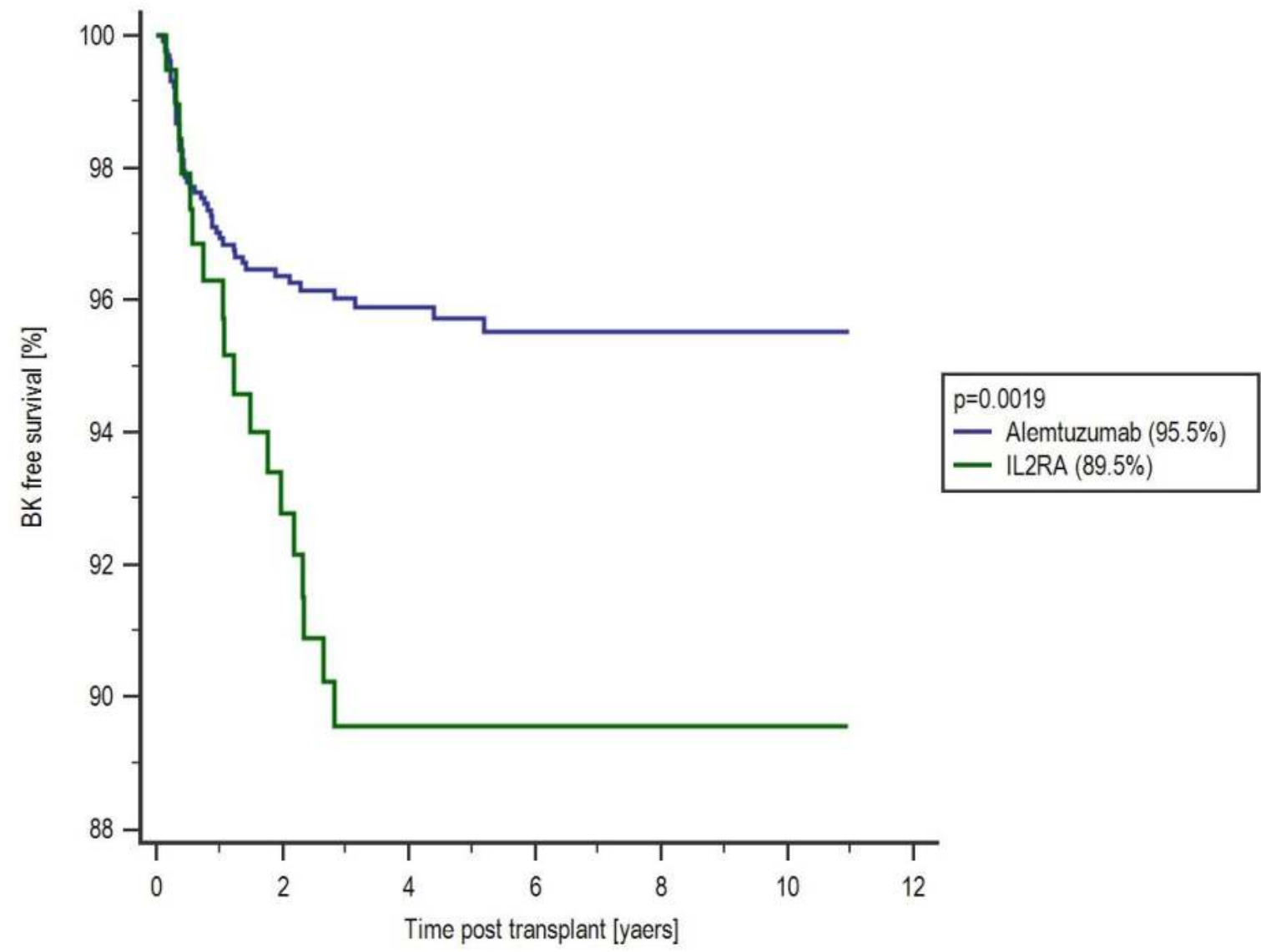

\section{Censored Allograft Survival in Patients on MMF vs CNI Monotherapy}

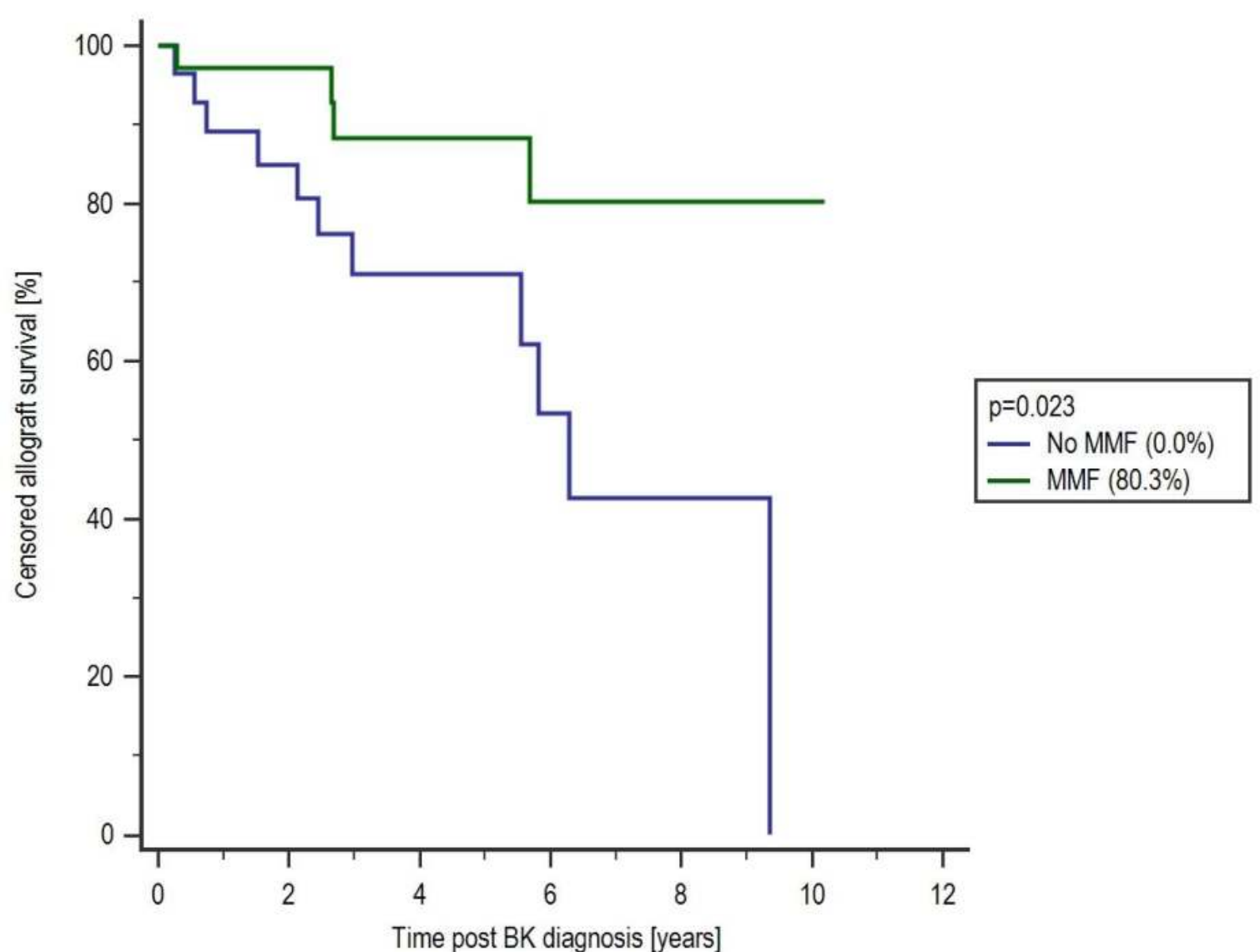

\section{Conclusions:}

[1]Induction with Alemtuzumab is associated with a lower incidence of BKVAN compared with IL2R antagonists.

[2]Patients on MMF at the time of BKVAN diagnosis had better allograft survival, presumably because we were able to stop MMF. 